such gels entirely unintelligible, and the experiment illustrating the retention of congo red by a gelatin gel must receive quite another explanation than that given to it.

\section{The Development of Vertebrates.}

Traité d'embryologie des vertébrés. Par Prof. A. Brachet. Pp. xvi +602 . (Paris : Masson et Cie., [92I.) 60 francs net.

F OR a remarkably clear and well-illustrated the student could not do better than turn to this textbook from the pen of the distinguished professor of the University of Brussels. The information given is thoroughly up-to-date, the conclusions for the most part convincingly supported by an abundance of facts marshalled with great skill. While the author does not hesitate to discuss controversial questions, yet this treatise is strikingly free from prejudice, and none the less interesting because it deals for the most part with matters of fact. We find none of the fantastic phylogenetic interpretations of developmental stages according to the recapitulation theory which disfigure so many general text-books of embryology.

Naturally, in a single volume of some 600 pages, the whole range of vertebrate embryology cannot be covered in detail, and it is the early stages and germlayer formation that receive particular attention. We know of no text-book in French or English with such a lucid account of these complex processes in the vertebrates. By skilful selection and the omission of unimportant detail Prof. Brachet also provides good descriptions of the development of the chief organs. The development of the cranial nerves, for instance, is particularly well presented.

There are some points on which the author is not convincing, and on which his conclusions might, we think, be revised and modified. In the account of the mesoblastic somites of the head, like so many other embryologists, he uncritically adopts van Wijke's scheme of enumeration, which inevitably leads to confusion in the region of the hyoid arch, instead of Balfour's system. We are unable to understand his reluctance to admit that in vertebrates above Amphioxus there are still traces of the formation of mesoderm from enterocoelic pouches, and we consider that he attaches too much importance to what he terms acrogenesis, cephalogenesis and notogenesis, a distinction which seems somewhat artificial and founded on certain specialisations of growth in the embryos of higher forms. Nevertheless, Prof. Brachet's volume is an excellent treatise, and will be heartily welcomed by students and teachers of embryology.

\section{Our Bookshelf.}

The Principle of Relativity. Original Papers. By A. Einstein and H. Minkowski. Translated into English by M. N. Saha and S. N. Bose. With a Historical Introduction by Prof. P. C. Mahalanobis. Pp. xxiii + I86. (Calcutta : University of Calcutta, I920.)

THE book under review begins with an interesting historical account of the experiments dealing with the elucidation of the æther-idea in physics, and we are led through the work of Michelson and Morley, Lorentz and others to a brief account of Einstein's theory of relativity and some of the results obtained with its aid. The second section reproduces Einstein's original paper "On the Electrodynamics of Moving Bodies" (Annalen der Physik, I905), and this is followed by a short note on Albrecht (!) Einstein and the various phases of his scientific activity. The next section on the "Principle of Relativity" is apparently a translation of Minkowski's paper on "The Fundamental Equations for the Electromagnetic Processes in Moving Bodies" (Göttinger Nachrichten, 1908), though no reference is given, and the title is omitted. An appendix to this is given, and it concludes with the wellknown lecture of Minkowski on "Space and Time," delivered to the German Naturforscherversammlung at Cologne (1908), and published in the Physikalische Zeitschrift (1909) and in "Das Relativitätsprinzip," a collection of papers by Lorentz, Einstein, and Minkowski (Teubner, I9I3). The sixth section of the book consists of Einstein's monumental work on the "General Theory of Relativity and Gravitation" (Annalen der Physik, I9I6), and the concluding section brings a number of explanatory notes, mostly mathematical, on special points.

The translation cannot be called a good one. In a work of this kind we expect a fairly literal translation, but in the present book there are numerous errors in translation, and the choice of English equivalents for German words is frequently unfortunate. In many instances the mathematics is faultily reproduced. The numbering of the pages is not continuous, but recommences at the beginning of section 4 , and the omission of the footnotes from the originals is regrettable. Provided it is studied with care, the translation will nevertheless be of service to those who are unfamiliar with German, and wish to grapple with the pioneer works on twis subject, some of which are rather inacressible.

A Little Book on Water Supply. By Dr. William Garnett. Pp. xv+r44. (Cambridge: At the University Press, 1922.) 6s. 6d. net.

"THIs little book when in manuscript was condemned by a very high authority on educational publications, for it did not enable the reader to prepare for any specific examinations." So the preface begins. But was not the very high authority anxious to be kind? We, too, are inclined to condemn the little book as an educational work, not because it is useless for examinations, but because it lacks a coherent plan.

There is no attempt to group the portions of letterpress into chapters. General statements are sand- 